\title{
Development and validation of an LC-MS/ MS method for monitoring larotrectinib, a tropomyosin-related kinase inhibitor, in mouse and human plasma and application to pharmacokinetic studies
}

Yoon-Jee Chae ${ }^{1 \dagger}$, Yoo-Kyung Song ${ }^{2 \dagger}$, Song-Hee Chae², Min Ju Kim², Jong Soon Kang ${ }^{2}$, Jae-Young Lee ${ }^{3}$, Tae-Sung Koo ${ }^{4}$ and Kyeong-Ryoon Lee ${ }^{2^{*}}$ (D)

\begin{abstract}
Larotrectinib is an orally administered drug and the first and only selective pan-tropomyosin receptor kinase (TRK) inhibitor in clinical development to treat cancer patients harboring a neurotrophic receptor tyrosine kinase gene fusion. In this study, an analytical method to quantify the TRK inhibitor in mouse and human plasma was developed and validated using LC-MS/MS following protein precipitation with acetonitrile. Larotrectinib and an internal standard (carbamazepine) were separated from endogenous substances using an Xterra C18 column with acetonitrile containing $0.1 \%$ formic acid as the mobile phase. The ions $\mathrm{m} / \mathrm{z} 429.8 \rightarrow 342.8$ for larotrectinib and $\mathrm{m} / \mathrm{z}$ $237.0 \rightarrow 194.0$ for carbamazepine detected in multiple reaction monitoring mode were used for the quantitation. The detector response of larotrectinib was linear within the concentration range 5-10,000 $\mathrm{ng} / \mathrm{mL}$ with a correlation coefficient $\left(r^{2}\right)$ of not less than 0.999 . The intra- and inter-day precision and accuracy were less than $10.48 \%$ and within $-8.99 \%$, respectively, in mouse and human plasma. Larotrectinib was stable under various storage and handling conditions, and no significant matrix effect was observed in both mouse and human plasma. Finally, the assay was successfully applied to the pharmacokinetic study of larotrectinib after its intravenous and oral administration to mice.
\end{abstract}

Keywords: Larotrectinib, TRK inhibitor, Pharmacokinetics, Mass spectrometry

\section{Introduction}

Tropomyosin receptor kinases (TRKs) are encoded by neurotrophic receptor tyrosine kinase (NTRK) 1/2/3 genes, and their expression is limited to the nervous system in normal condition. TRKs are reported to regulate pain, proprioception, appetite, and memory

\footnotetext{
* Correspondence: kyeongrlee@kribb.re.kr

${ }^{\dagger}$ Yoon-Jee Chae and Yoo-Kyung Song contributed equally to this work.

${ }^{2}$ Laboratory Animal Resource Center, Korea Research Institute of Bioscience and Biotechnology, Cheongju-si, Chungcheongbuk-do, Republic of Korea Full list of author information is available at the end of the article
}

(Nakagawara 2001, Chao 2003, Rubin and Segal 2004). However, if recurrent chromosomal fusion with other genes such as ETV6, LMNA, and TPM3 occurs as a result of a genetic rearrangement, it drives overexpression and ligand-independent activation, leading to activation of downstream pro-oncogenic pathways (Amatu, Sartore-Bianchi et al. 2016). Incidence of TRK fusion-positive cancers is estimated to be 1500-5000 patients in the USA annually with a lower prevalence in more common cancers such as non-small cell lung cancer or colorectal cancer and a higher prevalence in rare adult and pediatric cancers such as infantile
Springer Open

(c) The Author(s). 2020 Open Access This article is licensed under a Creative Commons Attribution 4.0 International License, which permits use, sharing, adaptation, distribution and reproduction in any medium or format, as long as you give appropriate credit to the original author(s) and the source, provide a link to the Creative Commons licence, and indicate if changes were made. The images or other third party material in this article are included in the article's Creative Commons licence, unless indicated otherwise in a credit line to the material. If material is not included in the article's Creative Commons licence and your intended use is not permitted by statutory regulation or exceeds the permitted use, you will need to obtain permission directly from the copyright holder. To view a copy of this licence, visit http://creativecommons.org/licenses/by/4.0/. 
fibrosarcoma, cellular congenital mesoblastic nephroma, and papillary thyroid cancer (Martin-Zanca, Hughes et al. 1986, Tognon, Knezevich et al. 2002, Chao 2003, Stransky, Cerami et al. 2014, Wu, Diaz et al. 2014, Créancier, Vandenberghe et al. 2015).

Larotrectinib is an orally administered drug and the first and only selective pan-TRK inhibitor in clinical development for the treatment of cancers associated with an NTRK gene fusion. The half-maximal inhibitory concentration $\left(\mathrm{IC}_{50}\right)$ of larotrectinib against TRK proteins is $5-11 \mathrm{nM}$ in vitro, and the inhibitory effect of larotrectinib is reportedly 100 times more selective for TRKs than for other kinases (Doebele, Davis et al. 2015). During clinical studies on larotrectinib in patients with an advanced solid tumor (phase I study in adult and phase I/II study in pediatric patients), a combined interim analysis was performed for TRK fusionpositive patients although only the results of 55 patients were available at the time of data cut-off (Drilon, Laetsch et al. 2018). Surprisingly, the overall response rate was $75 \%$ and the responses were observed regardless of tumor type, TRK fusion characteristics (i.e., the type of protein fused with TRK), and age. Clinically significant adverse events were uncommon and no discontinuation occurred due to an adverse event. In November 2018, larotrectinib received accelerated approval in the USA for the treatment of adult and pediatric patients with solid tumors that have a NTRK gene fusion without a known acquired resistance mutation (Scott 2019).

Recently, quantitative bioanalytical assay for larotrectinib using liquid chromatography-tandem mass spectrometry (LC-MS/MS) proved to be useful in quantification of larotrectinib in mouse plasma and tissue homogenates (Sparidans, Wang et al. 2018). Information on systemic drug exposure in pre-clinical species is of a great value for improving the safety and efficacy of therapeutic drug regimens, both during and after drug approval. Moreover, systemic exposure data of a drug in pre-clinical species is even more useful when it provides a link for interpretation of safety margin or effective exposure in humans. Therefore, the objective of this study was to develop a reliable and reproducible quantitation assay based on LC-MS/MS that is selective and sensitive for larotrectinib and applicable to both human and mice (i.e., a preclinical species that is typically used in efficacy and toxicity studies of anticancer agents). The analysis was assessed for selectivity, sensitivity, reproducibility, specificity, matrix effect, and stability in mouse and human plasma. Furthermore, the analytical method was applied to pharmacokinetic studies in mice, and pharmacokinetic parameters of larotrectinib following intravenous and oral administration were reported.

\section{Methods}

\section{Chemicals and reagents}

Larotrectinib was obtained from Medchemexpress (Monmouth Junction, NJ), and carbamazepine used as internal standard (IS) was purchased from Sigma-Aldrich (St. Louis, MO). Acetonitrile, methanol, distilled water, and formic acid of HPLC grade were obtained from JT Baker (Phillipsburg, NJ). All other solvents and chemicals were of the highest analytical grade available and were used without further purification.

\section{Preparation of solutions, calibration standards, and quality controls}

For preparation of a standard stock solution, larotrectinib was dissolved in acetonitrile at a concentration of 1 $\mathrm{mg} / \mathrm{mL}$. Standard working solutions were then prepared by serial dilution of the stock solution and were subsequently used for preparing calibration curve and quality control (QC) samples. An IS working solution containing carbamazepine $(50 \mathrm{ng} / \mathrm{mL})$ was also prepared in acetonitrile. Carbamazepine was used as an IS in this study because there was no IS candidate available with similar structure to larotrectinib, and the analytic method to the compound was well developed to fit various experimental settings (Lee, Chae et al. 2018). Calibration standard samples for larotrectinib were prepared by spiking blank mouse and human plasma with the working standard solutions to reach the final concentrations of 5, 10, 50,100, 500, 1,000, 5,000, and 10,000 ng/ $\mathrm{mL}$. Similarly, QC samples for larotrectinib were also prepared to reach the final concentrations of 15,500 , and $8,000 \mathrm{ng} / \mathrm{mL}$ in the blank plasma. All solutions and samples were stored at $-20^{\circ} \mathrm{C}$ during the assay.

\section{Instrumentation and LC-MS/MS conditions}

The bioanalytical assay for larotrectinib was carried out using an Agilent LC-MS/MS system (Agilent, Santa Clara, CA) consisting of an Agilent 1200 series HPLC system connected to an Agilent 6430 mass spectrometer equipped with a turbo electrospray interface. The elution was carried out using linear gradient of $0.1 \%$ formic acid in water and $0.1 \%$ formic acid acetonitrile $(95 \%: 5 \% \rightarrow$ $5 \%: 95 \%, \mathrm{v} / \mathrm{v})$ at a flow rate of $0.4 \mathrm{~mL} / \mathrm{min}$ with a reversed-phase high-performance liquid chromatography column (Xterra MS C18, particle size $5 \mu \mathrm{m}$, length and internal diameter of the column $50 \mathrm{~mm} \times 2.1 \mathrm{~mm}$; Waters, Milford, MA). The temperatures of the autosampler and column oven were maintained at $4{ }^{\circ} \mathrm{C}$ and $40^{\circ} \mathrm{C}$, respectively, during the analysis. Multiple reaction monitoring (MRM) data were collected in the positive ionization mode. The optimized instrument settings for the analysis were as follows: pressure of the curtain, 20 psi; pressure in nebulizer, $35 \mathrm{psi}$; pressure of heating gasses, $100 \mathrm{psi}$; temperature of source, $300^{\circ} \mathrm{C}$; voltages of 
collision energy, $29 \mathrm{~V}$ for larotrectinib and $15 \mathrm{~V}$ for carbamazepine. The samples were monitored at the following Q1/Q3 transitions $(\mathrm{m} / \mathrm{z}): 429.8 \rightarrow 342.8$ for larotrectinib and $237.0 \rightarrow 194.0$ for carbamazepine (IS). The Agilent software (Data Acquisition and Quantitative Analysis) was used for operation of the instrument and data collection of larotrectinib and carbamazepine.

\section{Sample preparation}

Mouse plasma of $10 \mu \mathrm{L}$ or human plasma of $50 \mu \mathrm{L}$ samples were transferred to fresh tubes and then mixed with 40 or $200 \mu \mathrm{L}$ IS working solution, respectively, for the plasma protein precipitation. The mixtures were vortexed for $5 \mathrm{~min}$ and centrifuged at $10,000 \mathrm{~g}$ for $10 \mathrm{~min}$. The supernatants were then transferred to a deep well plate and injected onto LC-MS/MS system.

\section{Method validation}

The analytical method for larotrectinib was validated following FDA guideline for bioanalytical method validation (FDA 2018). The intra-/inter-day accuracy and precision, along with sensitivity, selectivity, and linearity of the analytical method, was developed and evaluated. Multiple batches of calibration plasma samples were analyzed to evaluate the accuracy and precision of the newly developed analytical method. The variations of the intra-/inter-day measurements were calculated by the mean values of five replicates in four concentrations (i.e., $5,15,500$, and $8,000 \mathrm{ng} / \mathrm{mL}$ ) per day for 5 days. The accuracy was verified by the relative error (RE, \%; calculated concentration - theoretical concentration)/theoretical concentration $\times 100 \%$ ) using the calibration curve, and the precision was determined by the relative standard deviation (RSD, \%; standard deviation of concentration/mean concentration $\times 100)$ at each concentration. The selectivity for larotrectinib was determined by evaluating the chromatograms of (i) double blank plasma (no analyte, no IS), (ii) plasma spiked with analyte, (iii) plasma spiked with IS, and (iv) plasma spiked with both analyte and IS for possible interference by endogenous substances. The sensitivity for larotrectinib was evaluated by determining the lower limit of quantification (LLOQ) with good precision (i.e., less than 20\% RSD), and accuracy (i.e., less than $20 \% \mathrm{RE}$ ), and a signal-tonoise ratio equal to or greater than 10 . The calibration curve was constructed from the peak area of larotrectinib relative to the peak area of IS (i.e., peak area ratio), and the linearity of the calibration curve was examined in the concentration range of $5-10,000 \mathrm{ng} / \mathrm{mL}$. The linear regression analysis with a weighting factor of $1 / x$ ( $x$ is the concentration of larotrectinib) was performed to generate the calibration curve.

\section{Matrix effect}

Matrix effects for larotrectinib in mouse and human plasma were assessed at four different concentrations (5, 15,500 , and $8,000 \mathrm{ng} / \mathrm{mL}$ ). For each concentration, the peak areas of larotrectinib-spiked sample prepared in the post-precipitation matrix (set 1) were compared with those of the mobile phase sample spiked with corresponding concentrations of larotrectinib (set 2; reference standards). The matrix effect was also assessed for IS ( $25 \mathrm{ng} / \mathrm{mL})$ using similar methods.

\section{Stability}

The stability of larotrectinib was assessed in both mouse and human plasma for three QC levels (LQC, MQC, HQC; $15,500,8000 \mathrm{ng} / \mathrm{mL}$ ). The storage conditions simulated for larotrectinib stability test were as follows: (1) three freeze-thaw cycles; (2) plasma samples stored at room temperature, $4{ }^{\circ} \mathrm{C}$ or $-20^{\circ} \mathrm{C}$ for $24 \mathrm{~h}$, or at $-80^{\circ} \mathrm{C}$ for 4 weeks; and (3) post-preparative samples stored at room temperature for $24 \mathrm{~h}$, or at $4{ }^{\circ} \mathrm{C}$ for $24 \mathrm{~h} / 1$ week.

\section{Pharmacokinetic analysis}

Male ICR mice, 9 weeks old, were used for the pharmacokinetic study of larotrectinib. The mice were housed in plastic cages and given free access to standard mouse diet and drinking water. The room was maintained at $23^{\circ} \mathrm{C}$, relative humidity of $50 \%$, under a 12 -h light/12-h dark cycle. Following administration of $10 \mathrm{mg} / \mathrm{kg}$ oral or $5 \mathrm{mg} / \mathrm{kg}$ intravenous dose of larotrectinib, approximately $30 \mu \mathrm{L}$ blood was collected at 0 (pre-dose), 5 (intravenous only), 15, $30 \mathrm{~min}, 1,2,4,6$, and $8 \mathrm{~h}$ post-administration. The blood samples were centrifuged immediately after collection, and plasma fractions were stored at $-80^{\circ} \mathrm{C}$ until it was used in LC-MS/MS analysis.

A non-compartmental analysis was performed to calculate the pharmacokinetic parameters for larotrectinib using the Kinetica ${ }^{\mathrm{TM}}$ 4.4.1 software (Thermo Fisher Scientific, Inc., Woburn, MA, USA). The area under the plasma concentration-time curve $\left(\mathrm{AUC}_{\text {last }}\right)$ was obtained by applying the linear trapezoidal rule. The area under the plasma concentration-time curve from time zero to infinity $\left(\mathrm{AUC}_{\infty}\right)$ was obtained by applying the linear trapezoidal rule with the method of standard area extrapolation. The terminal half-life $\left(t_{1 / 2}\right)$ of the compound was calculated by dividing 0.693 with $\lambda$, where $\lambda$ represents the terminal log-linear slope of larotrectinib concentration-time profile. The total clearance $(\mathrm{CL})$ for larotrectinib was calculated using dose/AUC ${ }_{\infty}$, and the steady-state volume of distribution $\left(V_{\mathrm{ss}}\right)$ was then calculated by MRT $\times$ CL. The absolute oral bioavailability $(F$, $\%)$ was calculated by dividing the mean $\mathrm{AUC}_{\infty}$ after oral administration by the $\mathrm{AUC}_{\infty}$ after intravenous administration. The observed maximum concentration $\left(C_{\max }\right)$ and time to reach $C_{\max }\left(T_{\max }\right)$ were directly obtained 
from individual plasma concentration-time profiles of larotrectinib.

\section{Results and discussion}

Development of mass spectrometry and chromatography The chemical structures and product-ion scan spectra of larotrectinib and IS are shown in Fig. 1. The $m / z$ values for larotrectinib and IS were detected at $429.8>342.8$ and $237.0>194.0$, respectively. The chromatographic conditions in this study were appropriately adjusted to allow for high-throughput analysis while providing proper separation of larotrectinib and IS from the endogenous substances in plasma samples. The chromatographic run time was optimized to $9 \mathrm{~min}$ at the retention time of approximately 2.29 and $2.35 \mathrm{~min}$ for larotrectinib and IS, respectively, with adequate separation from other interfering peaks. The representative chromatographic peaks of larotrectinib and IS in MRM mode are depicted in Fig. 2. The obtained shape and retention times of larotrectinib and IS in all mouse and human samples were consistent throughout the analysis, indicating that the chromatographic development of the assay was adequate.

\section{Specificity, LLOQ, and linearity}

The mouse and human plasma samples were subjected to protein precipitation by adding four times volume of acetonitrile to the samples. No interfering chromatographic signal was observed near the retention times of larotrectinib or IS at the double-blank or blank plasma (i.e., IS spiked) samples, and a stable background baseline was observed throughout the assay (Fig. 2). Limit of quantification (LLOQ; $5 \mathrm{ng} / \mathrm{mL}$ ) was determined, and the precision and accuracy at LLOQ were both acceptable (\%RSD and \%RE $\leq 20 \%$ in both mouse and human plasma). The calibration curves of larotrectinib in mouse and human plasma were linear in the concentration range of $5-10,000 \mathrm{ng} / \mathrm{mL}$ under the assay conditions. The correlation coefficient $\left(r^{2}\right)$ was more than 0.999 by linear least squares regression analysis of peak area ratios of larotrectinib and IS against larotrectinib concentration in plasma samples, indicating that the signal of

(A)

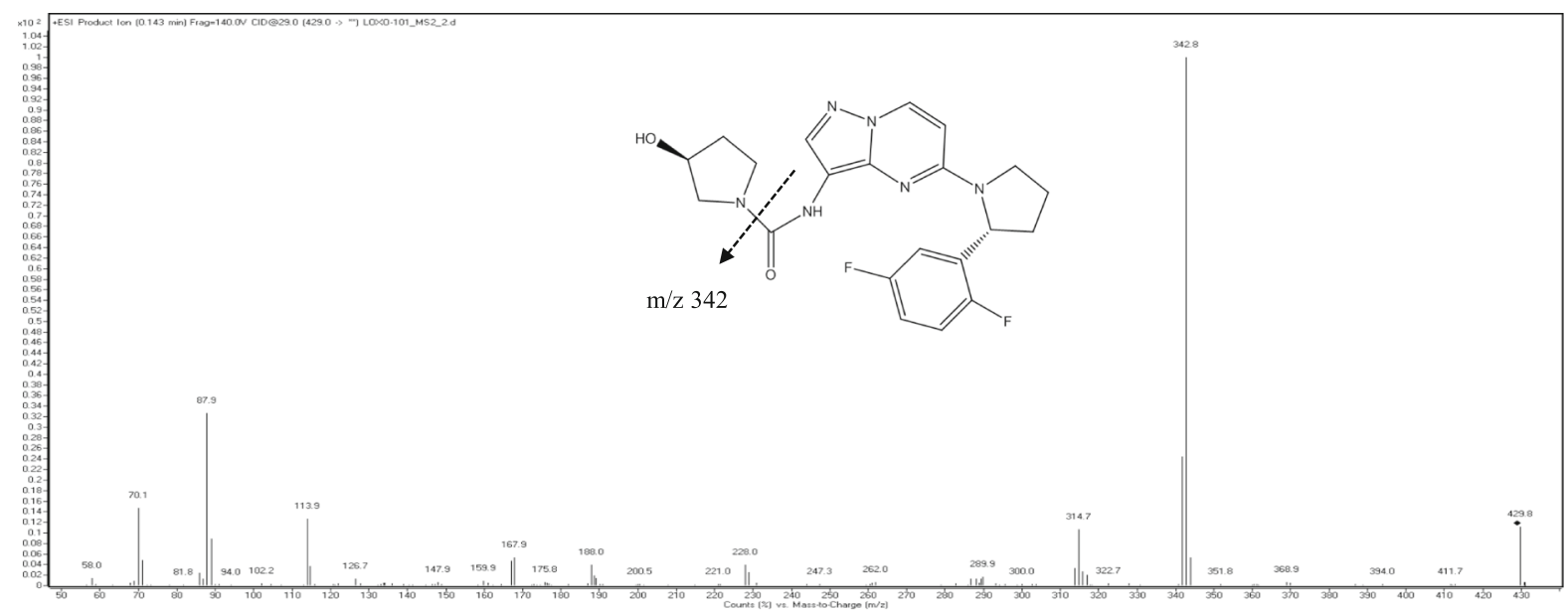

(B)

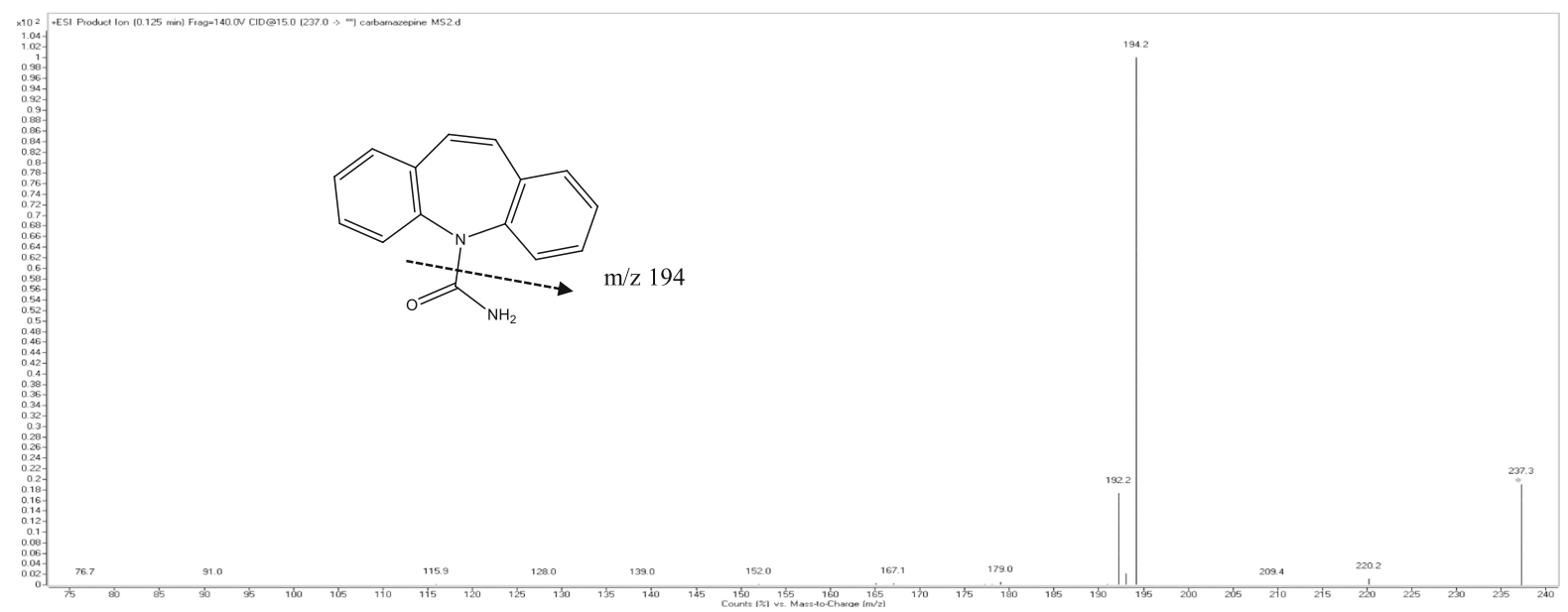

Fig. 1 The structures and product-ion scan spectra of a larotrectinib and $\mathbf{b}$ carbamazepine (IS) 


\section{Mouse plasma}

larotrectinib

(A)

(B)

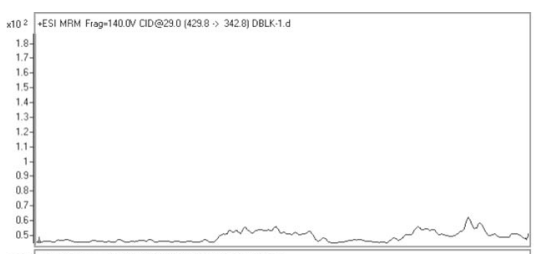

(C)
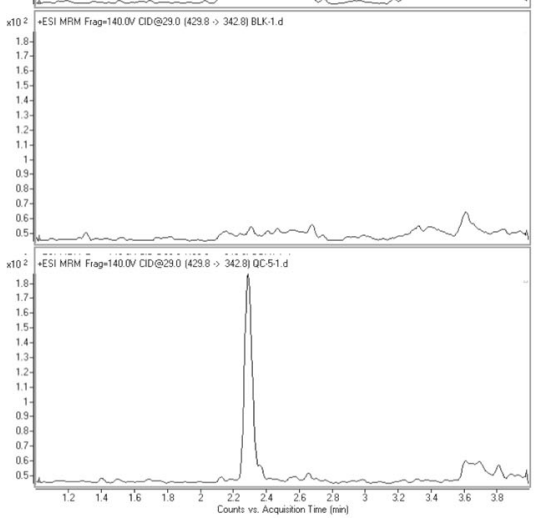

Human plasma

larotrectinib

(A)

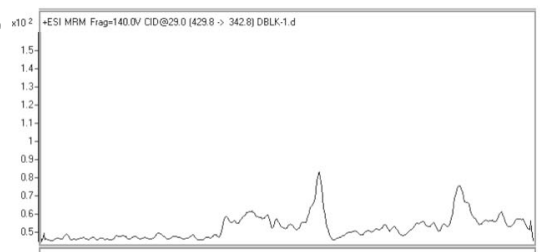

(B)

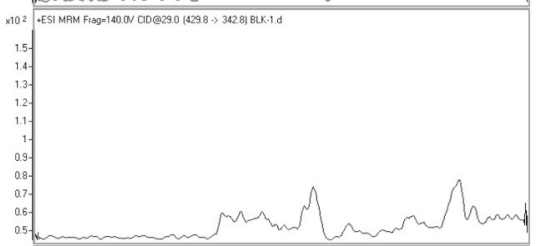

(C)

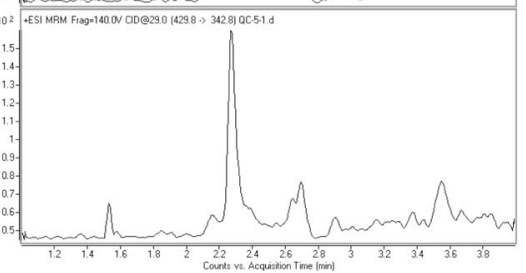

carmabazepine (IS)
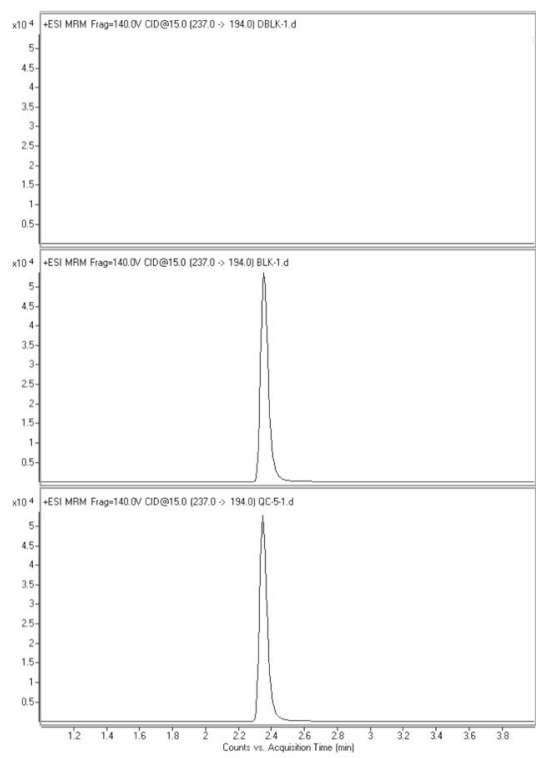

carmabazepine (IS)
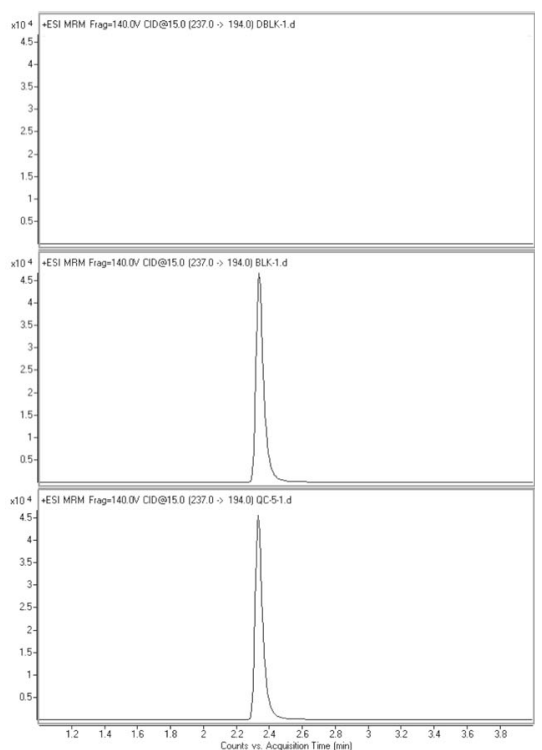

Fig. 2 Representative MRM chromatograms of a double blank plasma, b blank plasma spiked with IS, and c blank plasma spiked $5 \mathrm{ng} / \mathrm{mL}$ (LLOQ) of larotrectinib and IS

larotrectinib is well correlated to its plasma concentration in the LC-MS/MS analysis.

\section{Precision and accuracy}

The summary of intra-/inter-day precision and accuracy values for the assay are presented in Table 1. At four different concentrations of QC samples (LLOQ, LQC, MQC, HQC; 5, 15, 500, $8000 \mathrm{ng} / \mathrm{mL}$ ), precision of the assay was less than $10.48 \%$ and the accuracy was within $-8.99 \%$ in both mouse and human plasma. In mouse samples, the precision of larotrectinib was less than $2.99 \%$ and $6.93 \%$ RSD in intra- and inter-day, respectively, whereas the accuracy was within the range from 3.87 to $1.59 \%$ and from -7.27 to $4.93 \%$ in the intra- and inter-day test, respectively. In human samples, the precision of larotrectinib was less than $10.48 \%$ and $4.06 \%$ 
Table 1 Reproducibility and accuracy for larotrectinib in mice and human plasma $(n=5)$

\begin{tabular}{|c|c|c|c|c|}
\hline & \multicolumn{4}{|c|}{ Theoretical concentration $(\mathrm{ng} / \mathrm{mL})$} \\
\hline & LLOQ & LQC & MQC & HQC \\
\hline & 5 & 15 & 500 & 8000 \\
\hline \multicolumn{5}{|l|}{ Mice } \\
\hline \multicolumn{5}{|l|}{ (A) Intra-day accuracy and precision } \\
\hline Mean estimated concentration (ng/mL) & 4.90 & 14.42 & 495.89 & 8127.24 \\
\hline Precision (RSD $\left.{ }^{\mathrm{a}}, \%\right)$ & 2.62 & 2.76 & 2.99 & 1.37 \\
\hline Accuracy (RE $\left.{ }^{\mathrm{b}}, \%\right)$ & -1.99 & -3.87 & -0.82 & 1.59 \\
\hline \multicolumn{5}{|l|}{ (B) Inter-day accuracy and precision } \\
\hline Mean estimated concentration (ng/mL) & 4.64 & 14.90 & 524.64 & 8284.02 \\
\hline Precision (RSD $\left.{ }^{\mathrm{a}}, \%\right)$ & 6.93 & 1.26 & 6.46 & 0.63 \\
\hline Accuracy (RE $\left.{ }^{\mathrm{b}}, \%\right)$ & -7.27 & -0.64 & 4.93 & 3.55 \\
\hline \multicolumn{5}{|l|}{ Human } \\
\hline \multicolumn{5}{|l|}{ (A) Intra-day accuracy and precision } \\
\hline Mean estimated concentration (ng/mL) & 4.55 & 15.27 & 511.22 & 8100.98 \\
\hline Precision (RSD $\left.{ }^{a}, \%\right)$ & 10.48 & 0.77 & 0.44 & 1.21 \\
\hline Accuracy $\left(\operatorname{RE}^{\mathrm{b}}, \%\right)$ & -8.99 & 1.78 & 2.24 & 1.26 \\
\hline \multicolumn{5}{|l|}{ (B) Inter-day accuracy and precision } \\
\hline Mean estimated concentration (ng/mL) & 5.34 & 15.18 & 525.40 & 8223.77 \\
\hline Precision (RSD $\left.{ }^{\mathrm{a}}, \%\right)$ & 4.06 & 2.63 & 1.90 & 2.42 \\
\hline Accuracy (RE $\left.{ }^{\mathrm{b}}, \%\right)$ & 6.77 & 1.17 & 5.08 & 2.80 \\
\hline
\end{tabular}

${ }^{\mathrm{a}}$ standard deviation of concentration/mean concentration $\times 100 \%$

$\mathrm{b}$ (calculated concentration - theoretical concentration)/theoretical concentration $\times 100 \%$

RSD in intra- and inter-day, respectively, whereas the accuracy was within the range from -8.99 to $2.24 \%$ and from 1.17 to $6.77 \%$ in intra- and inter-day, respectively.

\section{Matrix effect}

The summary of matrix effects of larotrectinib and IS are presented in Table 2. At four different QC

Table 2 Matrix effect of larotrectinib and IS $(n=5)$

\begin{tabular}{lll}
\hline & Concentration $(\mathrm{ng} / \mathrm{mL})$ & Matrix effect ${ }^{\mathrm{a}}(\%)$ \\
\hline Mice & & \\
Larotrectinib & 5 & 110.73 \\
& 15 & 110.72 \\
& 500 & 91.23 \\
& 8000 & 98.94 \\
IS (carbamazepine) & 25 & 104.83 \\
Human & & \\
Larotrectinib & 5 & 99.56 \\
& 15 & 103.39 \\
& 500 & 101.32 \\
IS (carbamazepine) & 25 & 102.00 \\
\hline
\end{tabular}

${ }^{a}$ mean peak area of an analyte added post-precipitation (set 1)/mean peak area of the same analyte standards (set 2 ) $\times 100 \%$ concentrations $(5,15,500,8000 \mathrm{ng} / \mathrm{mL})$, the mean matrix effect ranged from 91.23 to $110.73 \%$ in mouse plasma and ranged from 99.56 to $103.39 \%$ in human plasma. For the IS $(25 \mathrm{ng} / \mathrm{mL})$, the mean matrix effect was 104.83 and $100.09 \%$ in mouse and human plasma, respectively. Overall, no significant matrix effect could be observed for both larotrectinib and IS.

\section{Stability}

The stability of larotrectinib was assessed in both mouse and human plasma by analyzing three different QC levels of larotrectinib (LQC, MQC, HQC; 15, 500, 8000 $\mathrm{ng} / \mathrm{mL}$ ) at varying storage and handling conditions (Table 3). Larotrectinib was considered relatively stable during the conditions, with overall stability within the range from -6.79 to $6.77 \% \mathrm{RE}$ and from -5.96 to $10.19 \% \mathrm{RE}$ in all mouse and human samples, respectively, compared with freshly prepared samples. Following three freeze-thaw cycles, the calculated concentrations of plasma samples were close to the theoretical value (from -6.77 to $5.65 \% \mathrm{RE}$ ) in all mouse and human samples. The short-term (i.e., equal to or less than $24 \mathrm{~h}$ ) stability of plasma samples ranged from -2.94 to $6.77 \% \mathrm{RE}$ in mouse plasma samples and ranged from -5.08 to 6.35 in human plasma samples. The long-term (i.e., 4 weeks) stability of plasma samples ranged from -6.01 to 
Table 3 Stability of larotrectinib in mice and human plasma $(n=5)$

\begin{tabular}{|c|c|c|c|c|c|c|c|c|c|}
\hline \multirow[t]{2}{*}{ Condition tested } & \multicolumn{3}{|l|}{ LQC (15 ng/mL) } & \multicolumn{3}{|c|}{ MQC (500 ng/mL) } & \multicolumn{3}{|c|}{ HQC (8000 ng/mL) } \\
\hline & Mean (ng/mL) & $\mathrm{RSD}^{\mathrm{a}}(\%)$ & $\mathrm{RE}^{\mathrm{b}}(\%)$ & Mean (ng/mL) & $\mathrm{RSD}^{\mathrm{a}}(\%)$ & $\mathrm{RE}^{\mathrm{b}}(\%)$ & Mean $(\mathrm{ng} / \mathrm{mL})$ & RSD $^{\mathrm{a}}(\%)$ & $\mathrm{RE}^{\mathrm{b}}(\%)$ \\
\hline \multicolumn{10}{|l|}{ Mice } \\
\hline Control samples (freshly prepared) & - & 0.66 & - & - & 1.78 & - & - & 1,73 & - \\
\hline Freeze-thaw $\left(-80^{\circ} \mathrm{C}, 3\right.$ cycles $)$ & 15.45 & 2.68 & 3.01 & 466.17 & 2.82 & -6.77 & 8205.57 & 2.08 & 2.57 \\
\hline Bench (RT, $24 \mathrm{~h}$ ) & 14.76 & 3.70 & -1.62 & 507.26 & 3.53 & 1.45 & 8456.82 & 0.58 & 5.71 \\
\hline Refrigerator $\left(4^{\circ} \mathrm{C}, 24 \mathrm{~h}\right)$ & 16.02 & 2.75 & 6.77 & 502.51 & 2.75 & 0.50 & 8368.14 & 0.43 & 4.60 \\
\hline Freezer $\left(-20^{\circ} \mathrm{C}, 24 \mathrm{~h}\right)$ & 14.56 & 0.55 & -2.94 & 486.76 & 1.29 & -2.65 & 8195.62 & 2.09 & 2.45 \\
\hline Freezer $\left(-80^{\circ} \mathrm{C}\right.$, 4 weeks $)$ & 15.08 & 1.69 & 0.54 & 469.95 & 2.63 & -6.01 & 7988.80 & 0.32 & -0.14 \\
\hline Post-preparative (RT, $24 \mathrm{~h}$ ) & 14.74 & 0.86 & -1.76 & 504.12 & 4.51 & 0.82 & 8319.10 & 1.62 & 3.99 \\
\hline Post-preparative $\left(4^{\circ} \mathrm{C}, 24 \mathrm{~h}\right)$ & 15.35 & 0.32 & 2.36 & 466.07 & 2.43 & -6.79 & 7845.21 & 1.35 & -1.93 \\
\hline Post-preparative $\left(4^{\circ} \mathrm{C}, 1\right.$ week $)$ & 14.54 & 0.76 & -3.04 & 484.56 & 1.11 & -3.09 & 7868.35 & 0.58 & -1.65 \\
\hline \multicolumn{10}{|l|}{ Human } \\
\hline Control samples (freshly prepared) & - & 9.51 & - & - & 4.15 & - & - & 0.22 & - \\
\hline Freeze-thaw $\left(-80^{\circ} \mathrm{C}, 3\right.$ cycles $)$ & 15.30 & 1.53 & 1.98 & 528.25 & 0.40 & 5.65 & 8264.74 & 0.65 & 3.31 \\
\hline Bench (RT, $24 \mathrm{~h}$ ) & 14.24 & 2.39 & -5.08 & 481.51 & 0.95 & -3.70 & 8377.79 & 0.82 & 4.72 \\
\hline Refrigerator $\left(4^{\circ} \mathrm{C}, 24 \mathrm{~h}\right)$ & 15.20 & 0.14 & 1.37 & 483.95 & 3.23 & -3.21 & 8368.67 & 1.98 & 4.61 \\
\hline Freezer $\left(-20^{\circ} \mathrm{C}, 24 \mathrm{~h}\right)$ & 15.23 & 1.54 & 1.55 & 531.76 & 1.03 & 6.35 & 7999.97 & 0.87 & 0.00 \\
\hline Freezer $\left(-80^{\circ} \mathrm{C}, 4\right.$ weeks $)$ & 14.82 & 2.07 & -1.17 & 540.29 & 1.39 & 8.06 & 8002.13 & 5.89 & 0.03 \\
\hline Post-preparative (RT, $24 \mathrm{~h}$ ) & 14.85 & 1.49 & -1.02 & 550.94 & 3.75 & 10.19 & 8335.96 & 1.60 & 4.20 \\
\hline Post-preparative $\left(4^{\circ} \mathrm{C}, 24 \mathrm{~h}\right)$ & 14.85 & 3.49 & -1.01 & 488.57 & 1.68 & -2.29 & 8307.94 & 1.05 & 3.85 \\
\hline Post-preparative $\left(4^{\circ} \mathrm{C}, 1\right.$ week $)$ & 15.37 & 1.68 & 2.50 & 470.24 & 2.17 & -5.95 & 8167.04 & 0.99 & 2.09 \\
\hline
\end{tabular}

${ }^{a}$ standard deviation of concentration/mean concentration $\times 100 \%$

$\mathrm{b}$ (calculated concentration - theoretical concentration)/theoretical concentration $\times 100 \%$

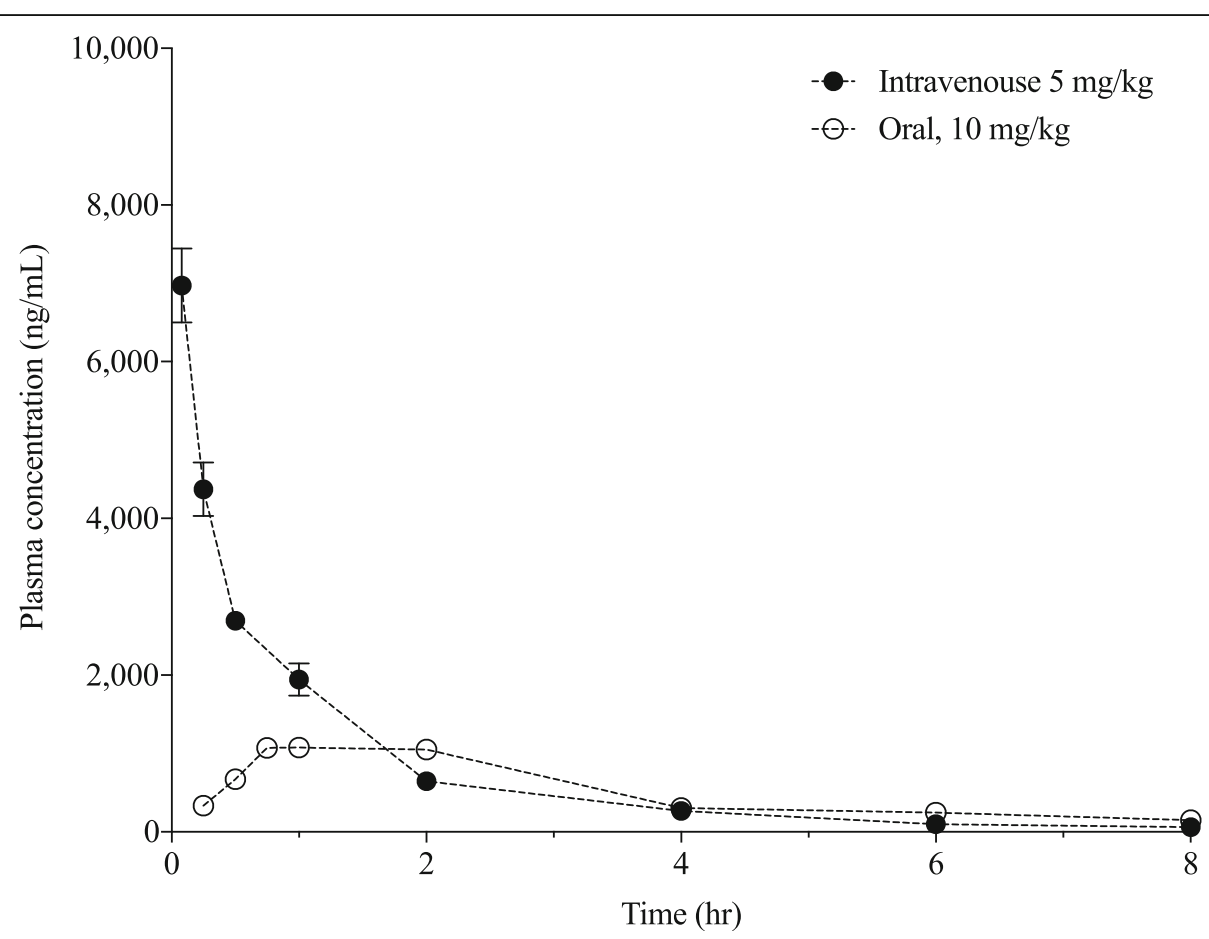

Fig. 3 Temporal profiles of larotrectinib concentrations in mouse plasma after an intravenous or oral administration of larotrectinib to mice (mean \pm standard deviation, $n=3$ ) 
$0.54 \% \mathrm{RE}$ and from -1.17 to $8.06 \% \mathrm{RE}$ in mouse and human samples, respectively. The stability in postpreparative samples ranged from -6.79 to $3.99 \%$ RE in mouse samples and ranged from -5.95 to $10.19 \%$ RE in human samples.

\section{Applicability to pharmacokinetic studies}

To determine whether the current quantitation assay may be applied to the pharmacokinetic study of preclinical species such as rodents, larotrectinib was orally and intravenously administered to mice and pharmacokinetic profile of the compound was examined. The plasma concentrations of larotrectinib were assessed after an intravenous administration of $5 \mathrm{mg} / \mathrm{kg}$ and oral administration of $10 \mathrm{mg} / \mathrm{kg}$ in mice (Fig. 3). Using the current assay, the plasma concentrations of larotrectinib following both oral and intravenous administrations were readily measurable in plasma samples collected up to $24 \mathrm{~h}$ post-administration. The pharmacokinetic parameters of larotrectinib were obtained by noncompartmental analysis (Table 4): $\mathrm{AUC}_{\text {last }}=6354.73 \pm$ $388.90 \mathrm{ng} \cdot \mathrm{h} / \mathrm{mL}, \quad \mathrm{AUC}_{\infty}=6503.94 \pm 403.92 \mathrm{ng} \cdot \mathrm{h} / \mathrm{mL}$, $T_{1 / 2}=1.74 \pm 0.11 \mathrm{~h}, \mathrm{CL}=0.77 \pm 0.05 \mathrm{~L} / \mathrm{h} / \mathrm{kg}, V_{\mathrm{ss}}=1.14$ $\pm 0.08 \mathrm{~L} / \mathrm{kg}, \mathrm{MRT}=1.48 \pm 0.01 \mathrm{~h}$ for $5 \mathrm{mg} / \mathrm{kg}$ intravenous administration and $\mathrm{AUC}_{\text {last }}=4026.00 \pm 111.83 \mathrm{ng} \cdot \mathrm{h} /$ $\mathrm{mL}, \mathrm{AUC}_{\infty}=4908.76 \pm 384.70 \mathrm{ng} \cdot \mathrm{h} / \mathrm{mL}, T_{\max }=1.25 \pm$ $0.66 \mathrm{~h}, C_{\max }=1103.33 \pm 70.95 \mathrm{ng} / \mathrm{mL}$ for $10 \mathrm{mg} / \mathrm{kg}$ oral administration. In addition, the drug appeared to be moderately absorbed with oral bioavailability of $31.70 \pm$ $0.88 \%$. The results suggested that the current quantitation assay is directly applicable to pharmacokinetic studies in mice after intravenous or oral administration at a larotrectinib dose of 5 or $10 \mathrm{mg} / \mathrm{kg}$, respectively. Assuming the efficacious concentration in human is similar to that in the mouse, the validated quantification range of larotrectinib in this study would be easily applicable in clinical trials for the quantification of larotrectinib in human plasma concentration as well.

Table 4 Summary of pharmacokinetic parameters for larotrectinib in mice (mean $\pm \mathrm{SD}, n=3$ )

\begin{tabular}{lll}
\hline Parameters & I.V. $(5 \mathrm{mg} / \mathrm{kg})$ & P.O. $(10 \mathrm{mg} / \mathrm{kg})$ \\
\hline AUC last $_{\text {la }}(\mathrm{ng} \cdot \mathrm{h} / \mathrm{mL})$ & $6354.73 \pm 388.90$ & $4026.00 \pm 111.83$ \\
$\mathrm{AUC}_{\infty}(\mathrm{ng} \cdot \mathrm{h} / \mathrm{mL})$ & $6503.94 \pm 403.92$ & $4908.76 \pm 384.70$ \\
$T_{1 / 2}(\mathrm{~h})$ & $1.74 \pm 0.11$ & - \\
$\mathrm{CL}(\mathrm{L} / \mathrm{h} / \mathrm{kg})$ & $0.77 \pm 0.05$ & - \\
$V_{\mathrm{sS}}(\mathrm{L} / \mathrm{kg})$ & $1.14 \pm 0.08$ & - \\
$M R T(\mathrm{~h})$ & $1.48 \pm 0.01$ & $4.70 \pm 0.90$ \\
$T_{\max }(\mathrm{h})$ & - & $1.25 \pm 0.66$ \\
$C_{\max }(\mathrm{ng} / \mathrm{mL})$ & - & $1103.33 \pm 70.95$ \\
$F^{\mathrm{a}}(\%)$ & - & $31.70 \pm 0.88$ \\
\hline
\end{tabular}

${ }^{a}$ calculated by $F(\%)=\frac{\mathrm{AUC}_{\mathrm{PO}}}{\mathrm{Dosepo}_{\mathrm{P}}} \times \frac{\mathrm{AUC}_{\mathrm{N}}}{\mathrm{Dose}_{\mathrm{N}}} \times 100(\%)$

\section{Conclusions}

An LC-MS/MS assay for quantifying larotrectinib in mouse and human plasma was developed and validated using MRM in positive ion mode. The selectivity, sensitivity, reproducibility, linearity, and specificity of the assay was validated in both mouse and human plasma. Larotrectinib was stable in mouse and human plasma samples under the described storage or handling conditions, with no significant matrix effect observed in both matrices. The assay was successfully applied to pharmacokinetic study in mice in which larotrectinib was moderately absorbed with oral bioavailability of $31.70 \pm$ $0.88 \%$ and is expected to be equally applicable for assessing the pharmacokinetics of larotrectinib in clinical trials.

\section{Abbreviations}

TRK: Tropomyosin receptor kinase; NTRK: Neurotrophic receptor tyrosine kinase; LC-MS/MS: Liquid chromatography-tandem mass spectrometry; IS: Internal standard; QC: Quality control; LLOQ: Lower limit of quantification; RE: Relative error; RSD: Relative standard deviation; AUC: Area under the plasma concentration-time curve; MRM: Multiple reaction monitoring

\section{Acknowledgements}

Not applicable.

\section{Authors' contributions}

YJ Chae, SH Chae, MJ Kim, and KR Lee designed and performed the research. YJ Chae, YK Song, JS Kang, JY Lee, and TS Koo designed and analyzed the data. YJ Chae, YK Song, and KR Lee wrote the manuscript. The authors read and approved the final manuscript.

\section{Funding}

This research was supported by a grant received from the Korea Research Institute of Bioscience and Biotechnology (KRIBB) Research Initiative Programs.

\section{Availability of data and materials}

Research data have been provided in the manuscript and supporting information files.

\section{Competing interests}

The authors have declared no conflicts of interest.

\section{Author details}

${ }^{1}$ CKD Research Institute, Yongin-si, Gyeonggi-do, Republic of Korea. ${ }^{2}$ Laboratory Animal Resource Center, Korea Research Institute of Bioscience and Biotechnology, Cheongju-si, Chungcheongbuk-do, Republic of Korea.

${ }^{3}$ College of Pharmacy, Chungnam National University, Daejeon, Republic of Korea. ${ }^{4}$ Graduate School of New Drug Discovery and Development,

Chungnam National University, Daejeon, Republic of Korea.

Received: 7 November 2019 Accepted: 28 May 2020

Published online: 03 June 2020

\section{References}

Amatu, A, A Sartore-Bianchi and S Siena. "NTRK gene fusions as novel targets of cancer therapy across multiple tumour types." ESMO open. 2016;1(2): e000023.

Chao, MV. "Neurotrophins and their receptors: a convergence point for many signalling pathways." Nature Reviews Neuroscience. 2003;4(4):299.

Créancier, L, I Vandenberghe, B Gomes, C Dejean, J-C Blanchet, J Meilleroux, R Guimbaud, J Selves and A Kruczynski. "Chromosomal rearrangements involving the NTRK1 gene in colorectal carcinoma." Cancer letters. 2015; 365(1):107-111.

Doebele, RC, LE Davis, A Vaishnavi, AT Le, A Estrada-Bernal, S Keysar, A Jimeno, M Varella-Garcia, DL Aisner and Y Li. "An oncogenic NTRK fusion in a soft tissue 
sarcoma patient with response to the tropomyosin-related kinase (TRK) inhibitor LOXO-101." Cancer discovery. 2015:CD-15-0443.

Drilon, A, TW Laetsch, S Kummar, SG DuBois, UN Lassen, GD Demetri, M Nathenson, RC Doebele, AF Farago and AS Pappo. "Efficacy of larotrectinib in TRK fusion-positive cancers in adults and children." New England Journal of Medicine. 2018;378(8):731-739.

FDA. "Bioanalytical method validation: guidance for industry." 2018.

Lee, KR, SH Chae, MJ Kim, YJ Chae, MY Lee, CW Lee, JS Kang, WK Yoon, YS Won and K Lee. "Determination of Penicillium griseofulvum-oriented pyripyropene $A$, a selective inhibitor of acyl-coenzyme A: cholesterol acyltransferase 2 , in mouse plasma using liquid chromatography-tandem mass spectrometry and its application to pharmacokinetic studies." Biomedical Chromatography. 2018:e4388.

Martin-Zanca, D, SH Hughes and M Barbacid. "A human oncogene formed by the fusion of truncated tropomyosin and protein tyrosine kinase sequences." Nature. 1986;319(6056):743.

Nakagawara A. Trk receptor tyrosine kinases: a bridge between cancer and neural development. Cancer letters. 2001;169(2):107-14.

Rubin JB, Segal RA. Growth, survival and migration: the Trk to cancer. Signal Transduction in Cancer, Springer. 2004:1-18.

Scott LJ. Larotrectinib: first global approval. Drugs. 2019;79(2):201-6.

Sparidans, RW, Y Wang, AH Schinkel, JH Schellens and JH Beijnen. "Quantitative bioanalytical assay for the tropomyosin receptor kinase inhibitor larotrectinib in mouse plasma and tissue homogenates using liquid chromatographytandem mass spectrometry." Journal of Chromatography B. 2018;1102:167172.

Stransky, N, E Cerami, S Schalm, JL Kim and C Lengauer. "The landscape of kinase fusions in cancer." Nature communications. 2014;5:4846.

Tognon, C, SR Knezevich, D Huntsman, CD Roskelley, N Melnyk, JA Mathers, L Becker, F Carneiro, N MacPherson and D Horsman. "Expression of the ETV6NTRK3 gene fusion as a primary event in human secretory breast carcinoma." Cancer cell. 2002;2(5):367-376.

Wu, G, AK Diaz, BS Paugh, SL Rankin, B Ju, Y Li, X Zhu, C Qu, X Chen and J Zhang. "The genomic landscape of diffuse intrinsic pontine glioma and pediatric non-brainstem high-grade glioma." Nature genetics. 2014;46(5):444.

\section{Publisher's Note}

Springer Nature remains neutral with regard to jurisdictional claims in published maps and institutional affiliations.

\section{Submit your manuscript to a SpringerOpen ${ }^{\circ}$ journal and benefit from:}

- Convenient online submission

- Rigorous peer review

- Open access: articles freely available online

High visibility within the field

- Retaining the copyright to your article

Submit your next manuscript at $\boldsymbol{\nabla}$ springeropen.com 